\title{
Fractal Geometry in Designing and Operating Water Networks
}

\author{
Małgorzata Iwanek ${ }^{1 *}$, Dariusz Kowalski', Beata Kowalska', Paweł Suchorab \\ ${ }^{1}$ Lublin University of Technology, Faculty of Environmental Engineering, ul. Nadbystrzycka 40B, 20-618 Lublin, \\ Poland \\ *Corresponding author's e-mail:m.iwanek@pollub.pl
}

\begin{abstract}
Fractals are self-similar sets that cannot be easily described by classical geometry. Fractal sets have been implemented in almost all areas of human activity since they were introduced to science by Mandelbrot in 1982. For the last 10 years, the interest in fractal geometry has increased by the issues connected with water distribution networks (WDNs). The aim of this paper was to review the application of fractal geometry in designing and operating WDNs. Treating a WDN as a fractal pattern enables its description and classification, simplifies the assessment of a network reliability, helps to solve the problems of routing and dimensioning WDN, as well as enables to select the places to locate measurement points in a network to control water quality, pressure in pipes and water flow rate. Moreover, the application of tree-shaped fractal patterns to reflect WDNs helps to solve the problems of their optimization. Fractal geometry can be also applied to investigate the results of WDNs failures connected with leakage of water to the ground. Using fractal dimension of a pattern created by points reflecting places of water outflow on the soil surface after a prospective pipe breakage enables to determine the zone near a pipe, where the outflow of water on the soil surface is possible. It is an important approach for the security of humans and existing infrastructure. Usage of fractal geometry in description, optimisation and operation analysis of WDNs still continues, which confirms the efficiency of fractal geometry as a research tool. On the other hand, it can be supposed that fractal geometry possibilities have still not been fully used.
\end{abstract}

Keywords: water distribution network, fractal features, tree-shaped pattern, fractal dimension

\section{INTRODUCTION}

Fractals are geometrical sets that are difficult to describe by classical geometry because of their high irregularity (Mandelbrot, 1975). Their main features cover self-similarity, fine structure at arbitrarily small scales, intricate detailed structure, recursive procedure of construction and size not quantified by the usual measures - e.g. length (Falconer, 1990). Many fractal patterns, especially occurring in nature, are not identical at all scales and their self-similarity is not exact. Such fractals are characterized by statistical or quasi self-similarity (Falconer, 1990, Hassan and Kurths, 2002, Barnsley et al., 2005).

A basic property of a fractal is its dimension. In contrast to Euclidian geometry, in fractal geometry, dimension is a measure of the spacefilling capacity of a set and can be a non-integer.
Moreover, a wide variety of definitions of fractal dimension was introduced. One of the most popular dimensions is the box-counting dimension, defined as (Falconer, 1990, Peitgen et al., 1997, Kudrewicz, 2015):

$$
D_{b}(F)=\lim _{\delta \rightarrow 0} \frac{\log N_{\delta}(F)}{-\log \delta}
$$

where: $F$ - non-empty bounded subset of $n$-dimensional Euclidian space, $D_{b}(F)$ - box-counting dimension of $F$, $N_{\delta}(F)$ - the smallest number of sets of diameter at most $\delta$ which can cover $F$.

Fractal structures have been implemented in almost all areas of human activity since they were introduced to science by Mandelbrot (1982). For the last 10 years, the interest in fractal geometry 
has increased by issues connected with water distribution networks (WDNs). This paper reviews applying fractal geometry in designing and operating WDNs.

\section{Networks as tree-shaped structures}

Tree-shaped structures are constructed by a sequence of affine transformations of an initial line segment. The process of construction can be described by the recursive formula (Kowalski, 2011):

$$
\left\{\begin{array}{c}
\text { initiator: } L_{0}, \\
L_{i+1} \rightarrow\left\{\begin{array}{l}
a \cdot L_{i}, \alpha^{\prime} \\
b \cdot L_{i}, \alpha^{\prime \prime} \\
c \cdot L_{i}, \alpha^{\prime \prime \prime}
\end{array}\right.
\end{array}\right.
$$

where: $L_{i}-$ length of $i$-th line segment $(i=0,1,2, \ldots)$,

$a, b, c-$ coefficients of line segments length generated in $i+1$ step,

$\alpha^{\prime}, \alpha^{\prime \prime}, \alpha^{\prime \prime \prime}-$ angles characterizing location of line segments generated in $i+1$ step in relation to the previous segment, wherein one endpoint of each new generated segment connects to the endpoint of previous line segment.

Assuming that $a=b=c$ and $\alpha^{\prime}=-\alpha ",, \alpha "=0$ Eq. (2) describes symmetrical tree-structure, constructed as given in Fig. 1.

WDNs can be reflected by tree-shaped structures; however, the following assumptions are suggested (Kowalski, 2011):

- lengths $a, b, c$ and angles $\alpha$, $\alpha$ ", $\alpha$ ", can take random values depending on a layout of the streets (which also can be treated as treeshaped structures - Bejan, 1996),

- a line segment ceases to be transformed, if $a, b$ or $c$ equals 0 ,
- an intersection of different line segments of the structure creates a new junction - one of the line sections with endpoint in the junction becomes an initiator for the next transformations,

- in the case of multi-supplied networks, each pipe supplying a network should be treated as independent initiator.

Considering the above assumptions, it is possible to reflect the branched, looped and mixed branched and looped networks, both single- and multi-supplied, by a tree-shaped structure according to Eq. (2) (Fig. 2).

It was verified that tree-shaped WDN can be treated as fractal set (Kowalski, 2011). The boxcounting dimension according to Eq. (1) for the network presented in Fig. 2 equals 1.087 if the sets covering the network are cubes or 0.870 if the sets are closed balls (Kowalski, 2011).

In some investigations, it is enough to reflect the WDN as a theoretical simplified pattern - e.g. regular tree-shaped structure (Fig. 3), following the assumption that the points where water is supplied are regularly displayed on a rectangle surface. An initiator can be of different form - not only a line segment. An example of tree-shaped WDS structure with X-shaped initiator is given in Figure 4.

An interesting approach to the fractal features assessment of the existing WDNs follows the box-covering algorithm for unweighted complex networks, previously reported in literature (Song et al., 2005, 2006, 2007, Kim et al., 2007, Gao et al., 2008). A network (structure $F$ according to symbols used in Eq. (1)) is treated as a fractal if the regression line for $\log \left(\mathrm{N}_{\delta}(\mathrm{F})\right)$ and $\log (\delta)$ is linear. The slope of the line denotes a fractal dimension $D_{b}$ defined by Eq. (1). This approach works well for different WDNs. Diao et al. (2017) investigated six real world WDNs this way and proved the existence of fractal patterns

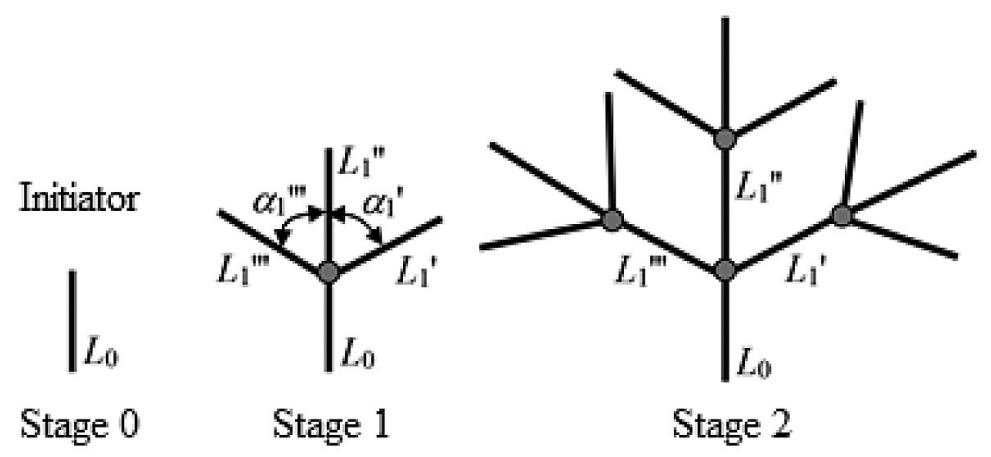

Fig. 1. Two stages of symmetrical tree-structure construction (Kowalski, 2011) 


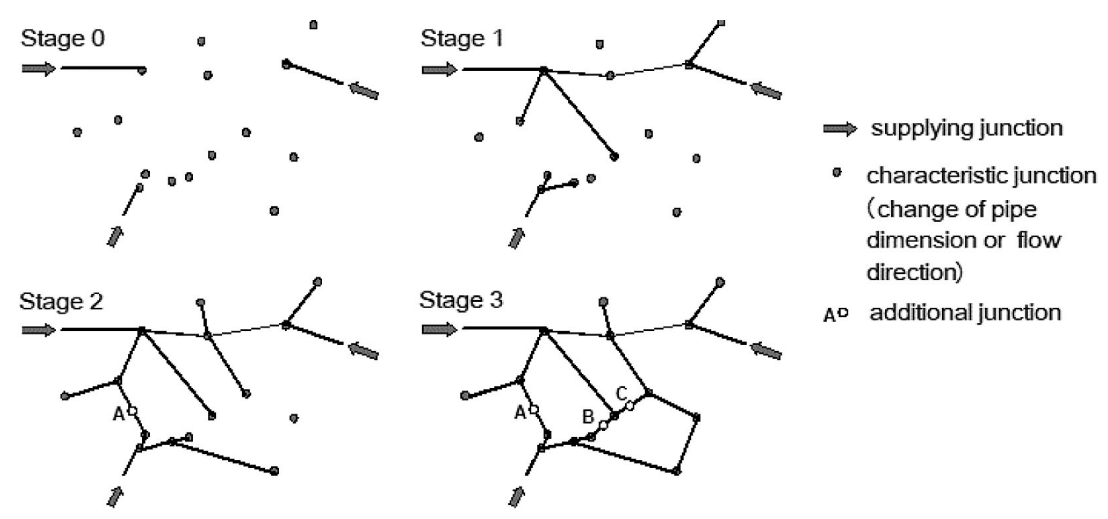

Fig. 2. Three stages of the tree-structure construction reflecting branched and looped network with three sources of water (Kowalski, 2011)

in all cases. The WDNs were different according to size, shape and complexity - consisting of 21 to 2465 links. Di Nardo et al. (2018) investigated two Italian networks similar to each other according to length (about $33 \mathrm{~km}$ ) and number of links (about 260), but different according to shape (elongated and compact), which also revealed fractal features. Vargas and Saldarriaga (2019a, $2019 b)$ proved the fractal properties of three different networks located in Colombia; however, they used the box-covering algorithm for weighted complex networks (Newman, 2004, Wei et al., 2013). The topology and hydraulic criteria were used to calculate the weight of each node of the network. The largest values of the fractal dimension were obtained with the topology weight criterion and there was no clear influence of the proposed hydraulic criteria on the fractal dimension results for the analysed WDNs (Vargas and Saldarriaga, 2019a).

\section{Applications of water networks fractal features}

Treating a WDN as a fractal pattern offers new opportunities for investigators, designers and operators of water distribution systems. One of the basic applications of the WDN fractal features is complementing the existing classification of water network structures, which specifies open systems - branched and radial, closed systems looped and ring-shaped, as well as mixed systems (Mielcarzewicz, 2000). So far, this classification has been supplemented by 2 parameters clearly
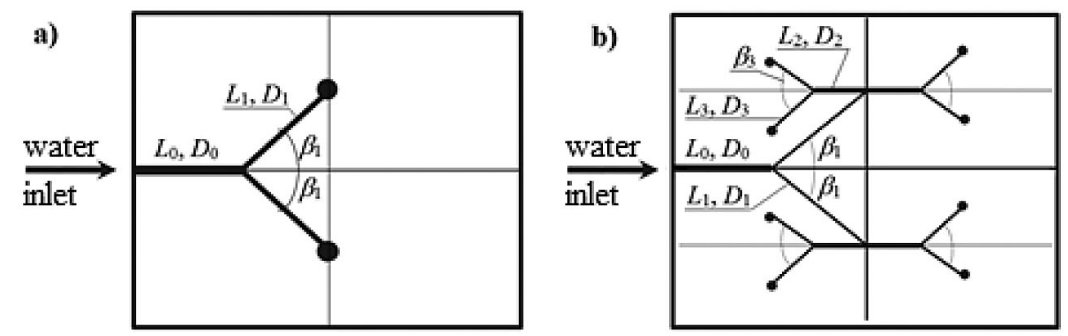

$L_{i}$ and $D_{i}$ - length and dimension of pipe in $i$-th stage

$\beta$ - angle angles characterizing location of line segments generated in $i+1$ stage
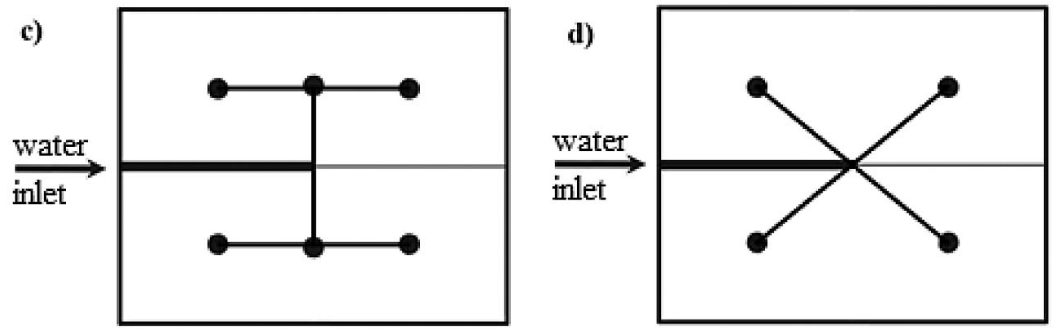

Fig. 3. Scheme of regular tree-structure constructions reflecting WDS (Azoumach et al., 2012): a) with Y-shaped branches (1st stage), b) with Y-shaped branches (2 stages),

c) with T-shaped branches (1st stage), d) with X-shaped branches (1st stage) 


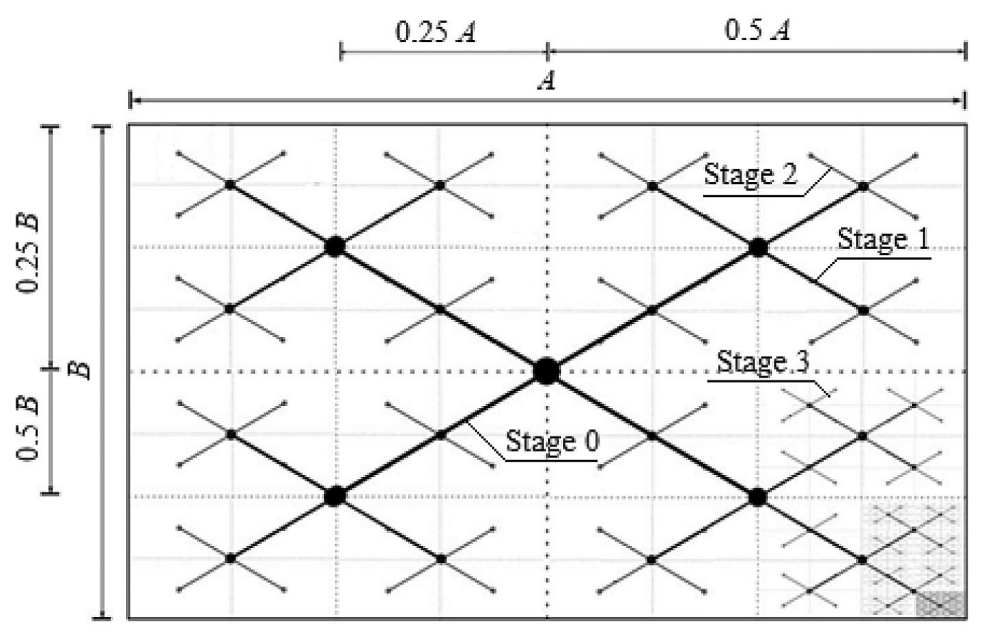

Fig. 4. Scheme of tree-structure construction reflecting WDS with X-shaped initiator and water inlet in the middle of rectangular area (Pauliuk et al., 2014)

characterizing WDN: total length of pipes and length of pipes in relation to the supplied area. These parameters allow differentiating the WDN systems specified in the classification by clear numerical values, but do not allow recognising the similarity of systems differing by scale only. For this purpose, the fractal features of WDNs are helpful. The value of a WDN box-counting dimension increases along with the complexity of systems and is constant for similar systems differing by scale of submitting. Thus, the WDN boxcounting dimension characterises a network better than pipes length divided by supplied area and can be treated as a parameter complementing the existing WDNs classification (Kowalski, 2011).

A box-counting dimension of a WDN geometrical structure can be also used for initial estimating reliability of water network structures. The relation between the dimension and a number of minimal efficiency paths (Kansal and Devi, 2007) was noticed during the analysis of 4 different models of WDNs and 3 actual WDNs (Kowalski, 2011). Although the number of analysed networks was insufficient to ascertain the functional dependence between these parameters, on the basis of the conducted investigations, a box-counting dimension was proposed for use as an indicator allowing to approximate evaluation of certainty of water delivery, especially for the analysis of complex WDNs structures.

Another way of using the WDNs fractal features to access the reliability of water network structures was presented by Di Nardo et al. (2018), who investigated the relationship linking the fractal and topological metrics of a WDN to its resilience to the failure of a pipe. The weighted $A P L$ (average path length), with the inverse of pipe diameter as weight, was introduced as a novel topological metric allowing to identify, without hydraulic simulations, the most important pipes and paths, the failure of which would significantly worsen the WDN operating conditions (Di Nardo et al., 2018). It is important that the $A P L$ is proportional to the number of nodes in the network treated as a fractal structure, raised to the power of inverse of the network fractal dimension (Csányi and Szendrői, 2004, Di Nardo et al., 2018).

Reliability in terms of the WDNs fractal features was also the subject of investigations by Zeng and Li (2013). They generated WDNs as fractal structures consisting of several basic patterns with different level of reliability and investigated the relationship between the reliability of basic patterns and the whole networks. The reliability of the whole network occurred consistent with the basic patterns composing it.

On the basis of fractality of different WDNs, Diao et al. (2017) developed a criticality analysis method to more efficiently identify all the critical pipes in WDNs than the traditional method. A pipe is regarded as critical if a loss of the pipe causes at least $10 \%$ of water supply shortage. During investigations, similar patterns of pipe criticality were observed both at different scales and at different parts of the WDN. This fractal-based observation allowed simplifying the analysis of WDNs.

Fractal features of WDNs and a box counting dimension were used by Zeng et al. (2017) to investigate the complex network model, which was developed following the combination of local optimization rules and engineering considerations. The simulation results indicated that the 
efficiency of WDNs is exponentially affected by the urban growth pattern.

The possibility of reflecting networks geometrical patterns by fractal tree-shaped structures was the basis of a new method for routing and dimensioning WDNs. The method uses the recursive procedure of fractal structure construction, minimal efficiency paths and modified Murray's law rule (Murray, 1926a, b). The method was effective both in the model network, and under the actual conditions (Kowalski, 2011). Moreover, the TRAS software - a tool for routing distribution networks, was designed by Suchorab and Kowalski (2019). The TRAS software has a hybrid character and was written in AutoLISP and $\mathrm{C}++$ programming languages, applying elements of fractal geometry and graph theory.

The WDNs fractal dimension can be used as a scaling factor indicating the network topological changes, depending on the scale in which the WDN is analysed (Vargas and Saldarriaga 2019a). Another application of the WDNs fractal dimension proposed by Vargas and Saldarriaga (2019b) is to identify the possible district metered areas (DMAs) in WDNs. By using the hydraulic criteria in the method's node weight calculations, the tests on three WDNs were carried out in order to establish the possible divisions into DMAs. The divisions were evaluated using the modularity index. The divisions obtained on the basis of the box covering algorithm using to calculate the fractal dimension were characterised by relatively high modularity, but lower than obtained with community detection. Divisions with relatively high modularity were obtained using the box covering algorithm, so the proposed method can be treated as a feasible alternative for identifying the potential divisions into DMAs in intricate WDNs.

The important issue for proper WDN operating is the system monitoring including the control of water quality, pressure in the pipes and water flow rate. The selection of places for locating the measurement points in a network is complex and problematic because of many reasons, e.g. quasi chaotic character of WDNs geometrical structure. In practice, this location has usually been imposed by the WDNs' operators; however, such a method does not meet a criterion of representativeness (Kwietniewski et al., 2005, Grzenda et al., 2010). A new proposal of measurement point location is based on fractal geometry. It uses the observation scale and recursive procedures. A departure from the Euclidian geometry rules enables to achieve universalism - possibility of application both in small, as well as large and complex WDN (Kowalski et al., 2015).

Another opportunity derived from WDN fractal features is facilitation of solving problems of WDN optimisation. Applying the tree-shaped fractal patterns to reflect WDN helps to find the best diameters scaling laws and optimal angles that minimise the total water head losses to the overall water residence time (Azoumah et al., 2012). Moreover, in the construction of WDN as a tree-shaped pattern, the method of exergy destruction minimisation is equivalent to minimising mechanical irreversibility under a water quality constraint (Bieupoude, et al., 2011).

\section{Application of fractal sets in investigations of water pipe failures}

Failures and breakages occur in WDNs all over the world (e.g. Ben-Mansour et al., 2012, Bakker et al., 2014, Berardi et al., 2014), creating not only onerous problems of water and financial losses for WDN exploiters (e.g. Eliades and Polycarpou, 2012, Deidda et al., 2014, Kutyłowska and Hotloś, 2014, Iwanek and Suchorab, 2017) but also the social and environmental risk connected with possibility of creation of empty spaces below the soil surface by the water flowing out from a damaged pipe under pressure (Iwanek et al., 2017, Kadetova et al., 2007, Khomenko, 2009). The empty spaces are dangerous especially in urban areas, because they can cause depressions or holes on the soil surface, threatening the vehicles on roads, existing infrastructure or even human life. One of the methods for limiting the adverse consequences of the accidents of this kind is to establish a protection zone on the soil surface over a buried water network, where the outflow of water is possible after a prospective failure of the pipe (Iwanek, 2018). Infrastructure and settlement in this zone should be carefully planned in order to exclude the possibility of diminishing the stability of objects as well as to limit social, financial and environmental costs in the case of water leakage from a pipe.

The water flow in soil after the breakage of a pressure water pipe is a complex phenomenon depending on many parameters, often connected with each other and varying in time or space (Iwanek and Suchorab, 2017), so the issue of the protection zone determination is challenging. The fractal dimension of a pattern created 
by the points reflecting places of water outflow on the soil surface after a prospective pipe breakage turned out to be a useful parameter. Iwanek (2018) proved that the location of points reflecting places of water outflow on the soil surface is random and the points create a structure meeting conditions which are characteristic for approximate fractals. On the basis of the points locations data obtained from the laboratory tests and the Monte Carlo simulations, a method for determining the representative structure was elaborated and the formula for the protection zone radius was determined as (Iwanek, 2018):

$$
\begin{gathered}
R_{f r-g r}=\left(\lim _{\delta \rightarrow 0} \frac{\log N_{\delta}(F)}{-\log \delta}\right) . \\
\cdot \max _{1 \leq i \leq n_{w g r}}\left\{\left(R_{w}\right)_{i} \mid i \in \mathbb{N}\right\}
\end{gathered}
$$

where: $R_{w}$ - horizontal distance between a place of leakage in a pipe and one of points creating a representative structure, reflecting place of water outflow on the soil surface $[\mathrm{m}]$, $n_{w g r}-$ number of points reflecting places of water outflow, creating a representative structure,

$\mathbb{N}$ - set of natural numbers, other symbols according to Eq. (1).

\section{CONCLUSIONS}

Many water networks display attributes of approximate fractals. Fractality of WDN structures provides a new perspective for understanding WDNs complexity and therefore for better description, optimisation and more effective operation analysis of WDNs. The fractal-based tools for classifying WDNs, estimating their reliability, routing and dimensioning networks, identifying DMAs in WDNs, selecting the places for locating measurement points, solving the optimization problems as well as establishing a protection zone in case of water pipe failure, have been developed for the last 10 years. So many different applications developed in relatively short period as well as different approaches to the fractal properties of WDNs confirm the possibilities and usefulness of the fractal-based research tools.

The research on using fractal geometry in design processes, maintenance, operational control or optimization of WDNs is still continued, what is important for designers and operators of all water distribution systems. However, it can be supposed that the fractal geometry possibilities have still not been fully recognized.

\section{Acknowledgements}

This article was funded by the statutory activity of the Faculty of Environmental Engineering, Lublin University of Technology.

\section{REFERENCES}

1. Azoumah Y., Bieupoude P., Neveu P. 2012. Optimal design of tree-shaped water distribution network using constructal approach: T-shaped and Y-shaped architectures optimization and comparison. International Communications in Heat and Mass Transfer 39(2), 182-189.

2. Bakker, M., Jung, D., Vreeburg, J., Van de Roer, M., Lansey, K., \& Rierveld, L. 2014. Detecting pipe bursts using Heuristic and CUSUM methods. Procedia Engineering, 70, 85-92.

3. Barnsley M., Hutchinson J., Stenflo Ö. 2005. A fractal valued random iteration algorithm and fractal hierarchy. Fractals 13(02), 111-146.

4. Bejan A. 1996. Street network theory of organization in nature. J. Adv. Transportation 30(2), 85-107.

5. Ben-Mansour R., Habib M.A., Khalifa A., YoucefToumi K., Chatzigeorgiou, D. 2012. Computational fluid dynamic simulation of small leaks in water pipelines for direct leak pressure transduction. Computers \& Fluids, 57, 110-123.

6. Berardi L., Liu S., Laucellii,D., Xu S., Xu P., Zeng W., Giustolisi O. 2014. Energy saving and leakage control in Water Distribution Networks: A joint research project between Italy and China. Procedia Engineering, 70, 152-161.

7. Bieupoude P., Azoumah Y., Neveu P. 2011. Environmental optimization of tree-shaped water distribution networks. Water resources management VI. Proc. of the sixth International Conference on Sustainable Water Resources Management, 99-109.

8. Csányi G., Szendrői B. 2004. Fractal-small-world dichotomy in real-world networks. Physical Review E, 70(1), 016122.

9. Deidda D., Sechi G. M., Zucca R. 2014. Finding economic optimality in leakage reduction: a costsimulation approach for complex urban supply systems. Procedia Engineering, 70, 477-486.

10. Di Nardo A., Di Natale M., Giudicianni C., Greco R., Santonastaso G.F. 2018. Complex network and fractal theory for the assessment of water distribution network resilience to pipe failures. Water Science 
and Technology: Water Supply, 18(3), 767-777.

11. Diao K., Butler D., Ulanicki B. 2017. Fractality in water distribution networks. Computing and Control for the Water Industry, Sheffield.

12. Eliades D. G., Polycarpou M.M. 2012. Leakage fault detection in district metered areas of water distribution systems. Journal of Hydroinformatics, 14(4), 992-1005.

13. Falconer K. J. 1990: Fractal Geometry: Mathematical Foundations and Applications. John Wiley, Chichester.

14. Gao L., Hu Y., Di Z. 2008. Accuracy of the ballcovering approach for fractal dimensions of complex networks and a rank-driven algorithm. Phys. Rev. E, 78, 046109.

15. Grzenda M., Sudoł M., Gębski W. 2010. Modelowanie systemu dystrybucji wody na przykładzie dużej aglomeracji miejskiej. Gaz, woda i technika sanitarna, 3, 2-6.

16. Hassan M.K., Kurths J. 2002. Can randomness alone tune the fractal dimension? Physica A, 315, $342-352$.

17. Iwanek M., Suchorab P., Karpińska-Kiełbasa M. 2017. Suffosion holes as the results of breakage of buried water pipe. Periodica Polytechnica - Civil Engineering 4(61), 700-705.

18. Iwanek M. 2018. Metoda wyznaczania zasięgu stref zagrożenia powodowanego przez rozszczelnienie podziemnych przewodów wodociągowych. Monografie, 146, Wydawnictwo Komitetu Inżynierii Środowiska PAN, Lublin.

19. Iwanek M., Suchorab P. 2017. The assessment of water loss from a damaged distribution pipe using the FEFLOW software. ITM Web of Conferences, 15,03006

20. Kadetova A.V., Rybchenko A.A., Trzhcinsky Y.B. 2007. Technogenic change of the geological environment of urban areas (by the example of Irkutsk

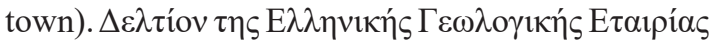
(Bulletin of the Geological Society of Greece), 40(3), 1440-1448.

21. Kansal M.L., Devi S. 2007. An improved algorithm for connectivity analysis of distribution networks. Reliability Engineering and System Safety, 92, 1295-1302.

22. Khomenko V.P. 2009. Suffosion hazard: today's and tomorrow's problem for cities. Engineering geology for tomorrow's cities, Geological Society. Engineering Geology Special Publication, London.

23. Kim J.S., Goh K.-I., Kahng B., Kim D. 2007. A boxcovering algorithm for fractal scaling in scale-free networks. Chaos 17, 026116.

24. Kowalski D. 2011. Nowe metody opisu struktur sieci wodociągowych do rozwiązywania problemów ich projektowania i eksploatacji. Monografie, 88,
Wydawnictwo Komitetu Inżynierii Środowiska PAN, Lublin.

25. Kowalski D., Kowalska B., Kwietniewski M. 2015. Monitoring of water distribution system effectiveness using fractal geometry. Bulletin of the Polish Academy of Sciences Technical Sciences, 63(1), 155-161.

26. Kudrewicz J. 2015. Fraktale i chaos. Wydawnictwo WNT, Warszawa.

27. Kutyłowska M., Hotloś H. 2014. Failure analysis of water supply system in the Polish city of Głogów. Engineering Failure, 41, 23-29.

28. Kwietniewski M., Gębski W., Wronowski N. 2005. Monitorowanie sieci wodociągowych i kanalizacyjnych, Wyd. Polskie Zrzeszenie Inżynierów i Techników Sanitarnych, Warszawa.

29. Mandelbrot B. B. 1982. The Fractal Geometry of Nature. W.H. Freeman and Co., New York.

30. Mandelbrot B.B. 1975. Stochastic models for the earth's relief, the shape and fractal dimension of coastlines, and the number area rule for islands. Proceedings of the National Academy of Sciences of the United States of America, 72 (10), 2825-2828.

31. Mielcarzewicz E. 2000. Obliczanie systemów zaopatrzenia w wodę, Arkady, Warszawa.

32. Murray C.D. 1926a. The physiological principle of minimum work applied to the angle of branching of arteries. J.Gen.Physiol., 9, 835-841.

33. Murray C.D. 1926b. The Physiological Principle of Minimum Work: I. The Vascular System and the Cost of Blood Volume. Proceedings of the National Academy of Sciences of the United States of America, 12(3), 207-214.

34. Newman M.E.J. 2004. Analysis of weighted networks. Phys. Rev. E, 70, 056131.

35. Pauliuk S., Venkatesh G., Brattebø H., Müller D.B. 2014. Exploring urban mines: Pipe length and material stocks in urban water and wastewater networks. Urban Water Journal, 11(4), 274-283.

36. Peitgen H.-O., Jürgens H., Sanpe D. 1997. Granice chaosu. Fraktale. Część 1. PWN, Warszawa.

37. Song C., Havlin S. Makse H. A. 2005. Self-similarity of complex networks, Nature, 433, 392-395.

38. Song C., Havlin S., Makse H.A. 2006. Origins of fractality in the growth of complex networks, Nature Physics, 2, 275-281.

39. Song C., Gallos L.K., Havlin S., Makse H.A. 2007. How to calculate the fractal dimension of a complex network: the box covering algorithm. Journal of Statistical Mechanics: Theory and Experiment, 2007(03), P03006.

40. Suchorab P., Kowalski D. 2019. Routing of branched water distribution networks using fractal geometry and graph theory. MATEC Web of Conferences, 
252, 02001.

41. Vargas K., Saldarriaga J. 2019a. Analysis of Fractality in Water Distribution Networks Using Hydraulic Criteria. World Environmental and Water Resources Congress 2019: Hydraulics, Waterways, and Water Distribution Systems Analysis, 564-572.

42. Vargas K., Saldarriaga J. 2019b. Potential District Metered Area Identification in Water Distribution Networks Using Hydraulic Criteria and the Box Covering Algorithm. World Environmental and Water Resources Congress 2019: Hydraulics, Waterways, and Water Distribution Systems Analysis, 573-586.
43. Wei D.J., Liu Q., Zhang H.X., Hu Y., Deng Y., Mahadevan S. 2013. Box-covering algorithm for fractal dimension of weighted networks. Scientific reports, 3(1), 1-8.

44. Zeng F., K. Li. 2013. Reliability Analysis of Fractal Water Distribution Networks Based on Basic Patterns, Proceedings of the 2013 Georgia Water Resources Conference, 2013, University of Georgia.

45. Zeng F., Li X., Li K. 2017. Modeling complexity in engineered infrastructure system: Water distribution network as an example. Chaos: An Interdisciplinary Journal of Nonlinear Science, 27(2), 023105. 